\title{
Eager to connect, cautious to consume: An integrated view of the drivers and motivations for electricity consumption among rural households in Kenya
}

Meron Tesfamichael ${ }^{1}$, Clifford Bastille ${ }^{2}$, Matthew Leach ${ }^{3}$

\footnotetext{
${ }^{1}$ Department of Science, Engineering, Technology \& Public Policy, University College London, Euston House, 24 Eversholt Street, London, NW1 1BS, United Kingdom

${ }^{2}$ Centre for Environment and Sustainability, Faculty of Engineering \& Physical Science, University of Surrey, Guildford, GU2 7XH, United Kingdom

${ }^{3}$ Centre for Environment and Sustainability, Faculty of Engineering \& Physical Science, University of Surrey, Guilford, Surrey, GU2 7XH, UK

Acknowledgment

This work was part of the Agro-Industries and Clean Energy in Africa project funded by the Engineering and Physical Sciences Research Council (EPSRC), the Department for International Development (DFID) and the Department for Energy and Climate Change (DECC) (grant ref EP/L002663)
}

Declaration of interest

No competing interests to declare 


\begin{abstract}
In the last ten years, electrification in Kenya has proceeded at an astonishing rate. Notwithstanding this feat, household electricity consumption, particularly in rural areas, remains significantly low. Thus, stimulating demand and sustainable consumption are the next critical challenges policymakers face. In this paper, we present a case study of an electrification project that targets workers' housing inside a commercial tea estate. We use Energy Cultures framework to analyse what motivates and constrains household electricity consumption in rural Kenya. Our findings show that although people give significant consideration to cost, money is not the only determinant. Electricity is desired to the extent that it enables families to carry out socially desirable activities, while service is measured against expectations and aspirations. Although access to the grid influences households' perceptions of wellbeing, their status as migrant workers has a constraining effect on how they consume electricity. Empowered by technology, households are also increasingly taking charge in shaping their own distinct energy cultures. However, for the most part, this involves finding new ways to reproduce and sustain a way of life that is consistent with their belief systems. Seeing households as embodiments of lifestyles whose energy culture is shaped by their on-going interactions with their physical and social environments, the paper argues for an integrated approach to policy and programmatic interventions.
\end{abstract}

\title{
1. Introduction
}

Electrification rates in Kenya are among the fastest in Africa. Motivated by a target to achieve universal electrification by 2022, over the years, the Government of Kenya, with support from international development partners, has introduced programmes to subsidise the capital cost of grid extension, the connection fee for rural households and a lifeline tariff for low-consumption households [1]. The Government has also restructured the energy sector to facilitate a private sector-led service provision in areas ranging from solar home systems to mini-grid projects. Subsequently, the combined effort has resulted in record-high electrification and connectivity rates in a short time period. Within the last 10 years, the number of households electrified has grown from 20 per cent to 70 per cent. Between 2010 and 2017, the number of customers connected to the national grid increased from 1.5 million to 6.17 million. Ninety-five per cent of those 6 million customers are households [2].

Studies show that despite these advances, consumption of electricity, especially among the more recently electrified households, remains significantly low [3]. One study finds that the average residential consumer in 2017 consumed 30 per cent of the electricity that the average residential consumer consumed in 2009. The researchers also note that urban households consume 50 per cent more electricity than rural households [4]. Based on data obtained from 
a private company operating mini-grids in Kenya, Osiolo et al. [1] report that the average monthly electricity consumption of rural consumers is $5 \mathrm{kWh}$, significantly lower than Nairobi, where it is 200kWh. According to the Kenyan Minister of Energy, most domestic power consumers are consuming "about ten units per month" and "paying about Sh200 a month" [5]. In the case study we present in this paper, an electrification project of workers' housing inside a commercial tea estate, we also found that households consume on average about $7 \mathrm{kWh}$ per month.

Lower than expected consumption is having a sobering effect on national energy ambitions. Recently, the Government announced that with demand growing slower than expected, it had reduced its 2030 power output target by 30 per cent - from $10 \mathrm{GW}$ to $7 \mathrm{GW}$ [5]. Stagnant demand is a concern for the electricity industry, whose overall operation relies on revenues from consumers, as well as a concern for energy service-providing companies, whose business models rely on a short-term return on investments. Modest consumption is of particular concern from the household perspective as it also means that families are missing out on the inherent benefits that are associated with access to modern and clean energy. Therefore, stimulating sustainable and healthy growth of consumption is a critical challenge policymakers and energy service providers face in Kenya.

For the most part, efforts to understand the reasons behind low electricity consumption focus on the economic and technical constraints consumers face. There is a broader recognition that households' electricity-consumption patterns are affected by economic, socio-demographic and physical characteristics. Income, the price of electricity and energy technology are often seen as key factors that regulate consumption [6]. Physical factors such as building type, size and number of bedrooms are also said to matter [7]. Others put emphasis on the characteristics of the dwellers, such as education level, age group, family composition and the number of adolescent children, as factors influencing households' energy use [8,9]. In Kenya, Lee et al. [10] observe that credit constraints, bureaucratic obstacles and the unreliability of existing power stifle household demand. Similarly, Osiolo et al. [1] note high poverty rates, lack of productive uses and insufficient disposable income as reasons for low consumption in rural Kenya. In this regard, to resolve the low uptake problem and stimulate demand, policymakers are often advised to address the techno-economic barriers such as reliability and quality [11]. 
While the techno-economic barriers undoubtedly influence how people access and consume energy, in the last three decades, within social sciences, more specifically within the disciplines of sociology and anthropology, there has been a growing interest in how norms, routine habits and social networks influence energy-consumption behaviour. A sociological approach to energy research, mainly working through the social practice theory lens, has been emphasising the importance of understanding households' energy needs and processes. This means shifting the focus away from the individual's decision-making process to seeing energy demand as a social construct where needs and expectations are part of a complex relationship between social norms, technologies, infrastructures and institutions [12-14]. Following this line of argument, others note that it is time to open "the black box of the household" and see how routines, values and practices that have developed over time shape households" "energy cultures" [15, p. 127]. Arguing that every day routines shape household energy demand, an analysis using practice theory seeks to understand how energy-related behaviours are formed and sustained through a closer examination of the components - technologies, embodied habits, meanings, materials and knowledge or competences - that hold the collectively shared practices together [16,17]. Seen in such a way, the practice, rather than the individual, is the focus of enquiry. The individual is recognised for her role as the carrier of the practice, but not necessarily the target of intervention [16]. With practice seen as the unit of analysis, the social practice theory moves beyond methodological individualism and recognise the agency of materials and technologies in the construction of daily routines.

This paper seeks to understand why electricity consumption among rural households in Kenya remains modest. We explore this question through a case study involving a workers' housing electrification project inside a commercial tea estate in western Kenya. The empirical research relies on interviews and a questionnaire-based survey of 41 households in four villages. Our aim is to peek into the "black box" (albeit briefly) and see what kind of impact the arrival of electricity had on households' energy cultures inside the estate. Our objective is two-pronged: first, to observe how interconnected societal structures such as social norms, technological infrastructure, physical artefacts and everyday routines interact to shape household energy behaviour; and second, to situate household energy demand and behaviour within a wider context of influences to discern what drives and motivates electricity consumption. We endeavour to examine how "the entanglements and interdependencies of social, political and technological elements" [18, p. 43] give rise to distinctive energy cultures, and highlight the relational and context-specific nature of households' energy behaviour [19]. 
We applied the Energy Cultures framework as an overarching framework to organise our enquiry [19-21]. The framework draws from multiple theories and explanations of behaviour to bridge "the divide between research traditions centred on the individual and those focused on wider social and technological influences" [19, p.117]. As a model of behaviour, the framework perspective is that subjects (in this case, households) have a distinct energy culture that is based on an on-going interaction between their norms, practices and material culture. Furthermore, their energy culture is shaped, but not fully determined, by external influences as well as their social and institutional setting [19]. As an analytical tool the Energy Cultures framework is diverges from the practice theory in two ways: first, it is centred on the subjects and their capacity to make choices and act; and second, it incorporates and pays attention to exogenous factors that might affect a household's energy behaviour. From our case-study perspective, the actor-centred approach is useful as it allows us to see electricity from the household viewpoint and capture families' dynamic relationships with the infrastructure. Thus far, the Energy Cultures framework has mainly been used to guide research on why sustainability-related outcomes are, or are not, being achieved [21, 22]. In this paper, we use the framework to structure our investigation into the complex and interconnected forces that shape household energy behaviour within a commercial tea estate, in rural Kenya.

The rest of the paper is organised as follows: in the following section, we outline theoretical perspectives related to energy consumption and discuss how we apply the Energy Cultures framework. The subsequent section introduces our case study. We follow this with a brief discussion of the research design and methods. We then report our findings. The final section offers an extended discussion and conclusion. In the conclusion, we use insights from the case study to draw lessons for policymakers and energy-service providers.

\section{Conceptual outline: Energy Cultures framework}

For the most part, explanations of what governs domestic energy consumption can be categorised in two parts: economic and non-economic influences. The economic or financebased explanation assumes household consumption is driven by price - the price of fuels, appliances, alternative energy resources - and by income constraints. The non-financial explanation focuses on socio-economic predictors such as age, gender, education and size of family, as well as psychological factors ranging from habits, norms and values, to belief systems, to decipher what drives behaviour. Rooted in economic and psychological theories, 
such accounts of household energy consumption emphasise the individualistic perspective [13]. Subsequently, efforts to stimulate demand or change behaviour tend to target and attend to identified barriers in isolation, often based on the assumption the individual is an autonomous decision maker and subject to external influences. However, in recent years, within the sociological discipline researchers have been questioning the relevance of individual decisions based on the view that needs and expectations are not individual but part of a complex relationships between norms, technologies, infrastructures and institutions [12] Following this growing recognition that the determinants of household energy behaviour are complex and include some combination of physical, technological, demographic, social and behavioural aspects, researchers are stepping away from discipline-based explanations to embrace a transdisciplinary approach to understand human-energy interactions [23, 24].

One way of understanding human-energy interactions is to see energy demand and consumption through the services "it makes possible" [25, p. 118] whether it is watching TV or cooking. Seen this way, understanding trends in energy demand is a matter of understanding how social practices emerge, evolve and intersect [26, p. 47]. This, subsequently, shifts the analytical lens away from "individual expression of preferences" towards an understanding of how energy is appropriated [27, p. 350]. Seen through the services it makes possible, demand is also seen to be embedded in an array of social processes, including daily habits and practices that take place within a broader social context of expectations and norms [28, p. 166]. For instance, in her study of energy consumers' behaviour, Kirsten Gram-Hanssen [17] identifies past experiences and daily routines; technologies including physical environment; and social norms as dispositions that inform households' energy consumption. Thus, confirming that consumption is informed by a complex and interdependent relationship between norms, technologies, infrastructures and institutions [12].

A sociological approach, mainly working through the social practice-theory lens, has been making significant contributions to understanding how people use energy to do the things they do. Research in this area focuses on the role of social practices, which are seen as networks of actions, materials and meanings. The extensive literature on the subject suggests that (energy) practices are held together by interconnected elements: norms and meanings; technology and physical objects; and competency and know-hows, while emphasising the material context and its impact on behaviour (the production and reproduction of practices) $[13,16]$. Here, what is 
of interest are the practices that underpin daily activities and how interaction between these elements can constitute practices.

The Energy Cultures framework is influenced by and draws on system thinking, practice theory and theory of structuration. The term "energy cultures" refers to clusters of knowledge, beliefs and material objects that have some bearing on the way people use energy [20]. Distinctive energy cultures arise from the on-going interactions between norms (aspirations and expectations); materials (physical aspects including appliances, buildings and infrastructure); and practices (from routinised activities to activities that may occur infrequently) [19]. The energy culture of a household, which is shaped by the interactions between the occupants' norms, practices and material culture, is also influenced by the broad spectrum of external influences [19]. With regards to household interaction with external influences, borrowing from systems thinking, the framework makes further distinction between transactional and contextual environments. Thus, suggesting that while households can interact with and influence their transactional environment, they must respond and adapt to their contextual environment [19, citing Russell L. Ackoff, 1974].

The framework architects emphasise that the idea is not to list all influences on behavioural outcomes, but to investigate the interrelationships between the elements as well as the role of external influences. In doing so, the framework is designed to bridge "the divide between research traditions centred on the individual and those focused on wider social and technological influences" [19, p.117]. One factor that set the Energy Cultures framework apart from the practice theory is that it invites a focus on actors and agency or the capacity of actors to make choices [30]. From our case-study perspective, the actor-centred approach is useful as it allows us to see electricity from the household viewpoint and capture families' dynamic relationships with the technological infrastructure [21]. The second factor that sets the framework apart from practice theory is its handling of exogenous influences. The framework architects argue that a household's distinct energy culture is shaped, although not fully determined, by societal and institutional settings within which the house is embedded. From our research perspective, incorporating the external influences or "the set of circumstances that form the contextual soup within which a given energy culture emerges and is sustained" $[19$, p.119] has been critical to our understanding of what drives and inhibits consumption. 
We use the Energy Cultures framework to observe how households incorporate electricity into their lives. First, we do this through an examination of the interplay between their daily energyrelated activities, the appliances they own, the physical artefacts that shape their worlds, and the social and personal norms they espouse. This process will allow us to understand the distinctive energy culture that has emerged within the estate following the arrival of the electricity grid. Second, we observe the effect external influences - the social, infrastructural and institutional settings within and outside the tea estate - have on the villages' energy culture and therefore consumption-related behaviour. We also seek to understand what households think and value about grid-based electricity by asking about their norms and aspirations. By doing this we seek to establish how households rationalise or justify their electricityconsumption patterns and the role of social norms. In this case, we also pay attention not only to estate-bound norms, but also to dominant social norms and how families' ways of life as migrant workers matter and define their energy cultures.

\section{Research context and methodology}

\subsection{Research context}

Kenya is one of the top global black tea producers, along with China and India. Western Kenya is historically a tea-growing area and home to large-scale commercial tea estates, including multinational tea companies such as James Finlay, Unilever, Williamson and the Kenya Tea Packers Limited. The area is a net recipient of migrants, with the tea estates as the principal destination. The case study for this paper was carried out inside the James Finlay commercial tea estate in Kericho town, western Kenya. James Finlay is a UK-based international company. The estate cultivates tea on 5500 hectares of land to produce about 30 million kilograms of tea annually. The company employs 12,500 people to work on the farm and the five factories inside the estate. There are over 200 villages inside the estate to house workers and their families. There are approximately 10,000 households and around 17,000 residents. Villages differ by size, with some containing as little as four houses, and others over 300. Besides housing, the commercial estate also holds 48 nursery schools, 14 primary schools, 13 dispensaries and two secondary schools, as well as other social-welfare services for workers and their families. There are different sizes of workers' accommodation across the estate, but the villages targeted for our case study contain two-room concrete structures, with bedrooms in the back and a front room that serves as the cooking, dining and living space. Toilets and shower rooms are located outside and are shared with others in the village. Each household has a kitchen garden and access to firewood from the forest within the estate. 
For large-scale commercial estates, in addition to providing essential social services like health care, education and housing, corporate social responsibility programmes (CSR) and philanthropy activities are part of workforce stabilisation and maintaining linkages with surrounding communities. CSR activities at James Finlays (hereon JF) range from providing scholarships to students to funding community-driven projects, among other activities. It is under these overarching initiatives that in $2014 \mathrm{JF}$ entered a partnership with an energy service company (ESCO), PowerGen, to extend power to the majority of the 200 villages that were not connected to the national grid. Although the factories and offices, as well as some residential quarters, are connected to the national electrical grid, the villages that were created to house workers did not have access. The partnership between JF and PowerGen was set up in such a way that JF covers the cost of households' connection and internal wiring, while PowerGen takes responsibility for the construction, operation and maintenance of the network. The actual electrification project followed two approaches: for villages close to the grid, a micro-grid distribution network that relied on the national grid network as its source; and a standalone solar-based micro-grid for villages that are far from the national grid.

Smart metering technology is at the centre of the electrification project. The smart meter is located within the customers' premises and includes a load switch, a two-way communication module and a data-gathering device, which is used to monitor the system in real time and allows a remote mobile-based payment. Families must have a mobile phone, an M-Pesa (mobile money) account and an account with PowerGen to access the service. Households pay a flat rate of 18 Kenyan Shillings (KSh) (0.18 USD) for every kWh of electricity used. At the beginning of each month, households must pay a standard fee of 222 KSh (2.21 USD). Users are asked to purchase the first $\mathrm{kWh}$ on a compulsory basis together with the standard monthly fee. Hence, the first purchase of the month, at a minimum, costs the user $240 \mathrm{KSh}$ (2.38 USD). After this initial payment, the user will have the option of topping up as needed or when he or she runs out of units. The pay-as-you-go system allows the user to control how much electricity he or she consumes, with an option to opt out of the service altogether.

\subsection{Research design and methods}

The empirical material for this exploratory study is drawn from two sources: questionnairebased semi-structured interviews with 41 households and unstructured interviews with individuals responsible for the operational and management aspects of the electrification 
project. Fieldwork was carried out from May to July 2018. The survey-based interviews were conducted in person inside the participants' premises. Sampling was a two-step process: we first identified the villages to target in consultation with the PowerGen team. Then, after informing the village elders and supervisors about the purpose of our visit, we approached households randomly.

The sampling of households focused on villages at different phases of the electrification project. For this, we targeted four villages: Mwamba (MW); Victoria (VI); Elgon (EL); and Tegencha (TE). At the time of the fieldwork, MW and VI villages had already had access to electricity for three years; EL village had been connected to the grid for three months; and TE village households were waiting to be electrified and did not yet have access to grid-based electricity. Residents in VI village are connected to a standalone solar-based micro-grid, while households in the MW village are connected to the grid. In total across the four villages there are 174 households. We approached about 50 per cent of the houses in each village, which adds up to 87 households, and 41 households agreed or were available to be interviewed. Of the 41 households we sampled, 15 (36.5 per cent) were residents of the MW and VL villages and 13 (31.7 per cent) of the EL village; the rest (13, or 31.7 per cent), were residents of the TE village. In addition to the households, we talked to a health-centre manager, teachers and estatemaintenance managers. By engaging villages at different phases of the electrification project, we wanted to see the variation in consumption and see if (and how) households' energy cultures evolve with time.

The questionnaire-based interview aimed to capture participants' accounts of how the arrival of electricity transformed their energy use. The questions were designed to prompt participants to discuss their experience using their own frames of reference. Questions such as "what are the benefits of electricity to you and people in your household?" aimed to understand the value occupants attach to electricity as manifested in the immediacy of their lived experience [31]. Close-ended questions like "do you think a unit of electricity is expensive?" were followed by "why?" for a further context-specific explanation. We wanted to understand what bearing norms, materials and practices have on the way they use energy and to what extent wider social and structural factors influence their consumption patterns.

We asked households about their financial spending patterns and what they see as the benefits of electricity to decipher families' aspirations and expectations, as well as how these factors 
inform their preferences and actions. By looking at household spending patterns, we aimed to understand what households prioritise and how they justify or rationalise their energy practices. By asking about the benefits of electricity, we wanted to observe how, through their consumption, families mirror and enact their values [32] and reproduce a way of life that is consistent with their belief systems [19]. We collected data on the types of energy households use, as well as the electrical appliances they own. For households that are yet to be electrified, we elicited their energy-related aspirations by asking what appliances they would like to own and why. Overall, questions were designed to gain insight into what households know and to what extent this knowledge is shaped by personal and social norms, lifestyle as migrant workers, and other contextual factors. We paid attention to the social meaning of electricity and the possibilities it affords from the households' perspectives.

Interviews and survey data were documented and coded into a spreadsheet based on the enduser category to draw out the themes relevant to our enquiry. In our analysis we focused on how participants relate their energy practices to their material culture and personal as well as social norms. We paid attention to the influencing effect of external factors like cost, technology, availability of alternative energy sources and institutional setting on household energy use. We also analysed experiences by gender, age groups, socio-economic status, family structure and other salient characteristics that would allow us to get a better insight into what interviewees were telling us. This allowed us to observe how the personal and the social are entwined and to what extent experience is shaped by the broader social, cultural and institutional narratives within which families live [31].

Despite the relevant findings of this study, there are some limitations: an investigation into household energy behaviour requires accessing intimate details about how families organise their daily routines and energy-based activities. From a methodological perspective, collecting and analysing such data requires an extended period of interactions and observation of households, the kind of time and engagement this research team was unable to allocate. For this, our analysis relies on the participants' descriptions. In other words, our data is limited to what respondents were able and willing to tell us. Therefore, our interviews are vulnerable to social-desirability bias, a tendency for participants to provide responses that they see as socially desirable (for an overview on the subject, see [33]). Recognising this possible drawback, we have augmented the interviewees and household survey with contextual inquiry approaches. We compared our findings with other studies conducted in the same or similar contexts and 
complemented the self-described consumption pattern with data from the supply side (the ESCO) to support the analysis.

\section{Findings and discussion}

Of the 41 households we interviewed, 23 are nuclear families; seven are single households (six female-headed, one male-headed); eleven are married but live alone with their families back in their home village (nine men, two women). Sixteen of those interviewed are female, 23 are male, and two were interviewed jointly. On average, there are three children (dependents) per family. Tea-estate workers are typically classified as either graded or ungraded. Graded jobs include supervisors, clerks and medical staff. Ungraded workers include tea pluckers, general farm workers (weeding, pruning, planting) and general factory workers (sorting, drying, packing, maintenance, cleaning). Almost all the households interviewed for this research are ungraded workers. Ungraded workers all earn the same amount and the salaries for each worker category are negotiated in a collective bargaining agreement every two years.

Household income can be categorised into three groups: regular salary from year-round employment; seasonal salary from nine months of employment per year; and income from selling groceries and other merchandise in the market. On average, households earn 17,714 KSh (175 USD) per month. However, monthly income varies for single and two-income households. For single-income households, monthly earnings range between 10,000 KSh and 15,000 KSh (100 to 150 USD). For two-income households, monthly income ranges between $22,000 \mathrm{KSh}$ to $30,000 \mathrm{KSh}$ ( 220 to $300 \mathrm{USD})$. Income tends to fluctuate for two groups: tea pickers who are paid for the leaves they pick in a day and per kilogram; and seasonal workers, who are employed for nine months a year. Seventy-five per cent of those interviewed said they also own a property outside the estate, whereas 39 per cent own a plot of land and keep livestock for sustenance.

Seventy-nine per cent of those interviewed said electricity is a basic need. Some said it is as essential as "water and food" (EL_F_37), ${ }^{1}$ while others endorsed it as a "must-have" (MW_M_43) and a thing "I cannot live without" (VI_M_35). However, despite the strong endorsements, household electricity consumption is modest across the three electrified villages. On average, families spend about $348 \mathrm{KSh}$ (3.44 USD) per month, or 2.8 per cent of

\footnotetext{
${ }^{1}$ Such labelling indicates that the person lives in Tegencha village (TE) and is a female (F). The number at the end is the interviewee's age and is used here as a unique identifier while also maintaining her anonymity.
} 
their calculated average monthly incomes, on electricity. This translates roughly to $7 \mathrm{kWh}$ per month with an average peak use of $100 \mathrm{~W}$. One-time spending of $300 \mathrm{KSh}(4 \mathrm{kWh})$ is enough to supply a month of electricity for households that use power for lighting (two $18 \mathrm{~W}$ bulbs for about four hours a day) and charging phones. This monthly power consumption also corresponds with electrical appliance ownership. For instance, families that own a television and a music set spend 500 to $600 \mathrm{KSh}$ (4.95-5.95 USD) per month on electricity. The majority of the households we interviewed said they spend a little over $300 \mathrm{KSh}$ (2.95 USD) per month.

If electricity is indeed a "basic need", why are households consuming so little of it? To answer this question, we explore how households' energy cultures changed following the arrival of electricity by paying attention to three factors: the physical artefacts and electrical appliances households own (material culture); the role of external influences and contextual factors in constraining and enabling households' electricity consumption; and how aspirations and expectations shape households' material cultures, attitudes about electricity and consumption. The energy cultures framework informs our approach. However, we also consider how wider social norms, such as group-membership signalling, influence households' energy behaviour. Second, we do not have a section dedicated to discussing "energy practices"; instead we reflect on and discuss an array of energy practices households are engaged in on a daily basis and the objects they acquire that enable them to enact and reproduce social practices. This follows the Stephenson et al [19] interpretation of "practices" as the usual and customary actions households carry out that are common occurrences across their social peers.

\subsection{Objects and appliances for daily use}

The arrival of electricity and associated infrastructure - the smart meter, the wooden pole and the wires hanging from it, as well as the light sockets and outlets fitting inside each house represent a new material culture that differentiate villages with electricity from those without electricity. However, when it comes to electrical appliances households acquire, there is less to differentiate one household from another. A mobile phone is the most prevalent object households within the tea estate own. Every household we interviewed, with access to electricity or not, owns at least one, and at most four, mobile phones. A solar home system is the second most acquired appliance. Seventy per cent of the respondents said they own a solar home product ranging from a torch to small panels that can power low-wattage appliances. The panels range from $5 \mathrm{~W}$ peak to $50 \mathrm{Wpeak}$, some with a battery for energy storage. Appliances associated with leisure activities are also prevalent and highly desired. Forty-nine per cent of 
those interviewed said they own a radio, either battery or solar-charged. Within the electrified villages, 26 per cent own a music set, and 32 per cent own a television. Only two families reported owning a DVD player and only one participant reported owning an electric hairclipper. Households in TE village said that once electrified they aspire to own a television (69 per cent), a music set (53 per cent), a refrigerator ( 38 per cent) and an iron ( 15 per cent).

Amongst households with electricity and regardless of how long they had been electrified, we observed no notable difference in appliance ownership. Households in the MW village, where occupants had had access to electricity for three years, and households in the EL village, where families had had access to electricity for three months, own the same set of appliances. However, we did observe a difference in appliance ownership between households with two incomes and a single income. Two-income households own relatively more appliances than those with a single income. For example, nine two-income households own a television, while only two single-income households own a television. On the other hand, in the yet-to-be electrified village (TE), regardless of income level participants expressed a strong desire to own high-wattage appliances such as refrigerators and irons.

Fuel (energy) stacking is practised widely within the estate, but more specifically for activities related to lighting and entertainment; for cooking, households rely almost exclusively on firewood. For lighting, only six households said they rely on electricity alone. Eighty-five per cent of the participants said that in addition to electricity they use solar products or kerosene lamps for lighting. A portion of households that are electrified also continue to use batteryoperated radios and appliances. Eighty-three per cent of the households interviewed use firewood for cooking. Only three households said they also use liquefied petroleum gas (LPG) in addition to firewood, and four households use kerosene on top of firewood. Reliance on firewood as a choice has been made easy by the fact that workers and their families can collect firewood within the estate at no financial cost. The inclination for firewood is reinforced by the preference for traditional cooking techniques and taste. The preference for traditional cooking is also reflected in households' attitudes towards the refrigerator, more specifically, a disinclination towards cold and preserved foods.

\subsection{The constraining and enabling influence of external factors}

One explanation for the modest electricity consumption among households within the estate is that families own just a few electrical appliances. One possible reason for this is limited 
physical space. Workers and their families live in two-room houses; therefore, even if they are able and willing to purchase many appliances, there is a practical space limitation on how many electrical objects they can accommodate. The influence of the floor area of a house on domestic electricity consumption has been well reported; the more rooms there are in domestic buildings, the more electricity its residents consume [7, 34]. As we discuss here, the physical infrastructure constrains and facilitates specific energy-consumption practices, ranging from cooking to socialising and keeping warm.

Demand-side management is another factor that curtails consumption. The service provider uses load limitation, which is set at five amperes at a voltage of 240 volts, to prevent the overloading of transformers and distribution lines. The five amps (equivalent to about $1000 \mathrm{~W}$ ) is the maximum electrical load a household can use at any given time. From the consumer's perspective, this means certain appliances and activities like an iron and cooking appliances are out of bounds. If a household uses a high-wattage appliance (like an iron), it would be difficult to use any other appliance at the same time (while ironing) because the maximum load of electricity is already reached. Furthermore, a high-wattage appliance like an iron is likely to gobble a household's credit rather quickly. Some of the typical appliances and activities that are within the 5amp limit are lighting, phone charging, radios, torches, televisions and laptop computers. However, usage also matters. A small refrigerator would meet the 5amp limit, but it would also gulp the credit much faster than, say, watching television for two hours every night. A refrigerator also cycles on and off automatically, and so might happen to draw power whilst other appliances are in use, with a risk of hitting the $5 \mathrm{amp}$ limit.

The load limitation also stands in contrast to households' general expectations and aspirations. As we gathered from our interviews, and as demonstrated by other studies in Kenya, for households that can afford it, once access to electricity is established, and basic needs like lighting and charging are met, aspirations jump to high-wattage appliances [1]. Lee et al. (2016) [10] in the survey they conducted in rural households in Kenya show that after lighting, the top three appliances households aspire to own are televisions, irons and refrigerators.

Cost is another important factor that influences household energy consumption. Over half of those interviewed deem the price of electricity per unit $(\mathrm{kWh})$ affordable, but the standard fee set by PowerGen (222 KSh/2.20 USD) as expensive. Household attitude about cost and "value for money" is informed by their direct experience and prior knowledge of how much the 
national utility, Kenya Power, charges. In our conversations on cost-related issues, participants often refer to how "cheap" electricity is outside the estate. For residential customers, Kenya Power does not charge anything for the first $50 \mathrm{kWh}$ per month. However, users are expected to pay the standard service fee (170 KSh/1.65USD) whether they use power for that month or not. Concerns about affordability appear to drive households' precautionary electricity consumption as well as dependence on multiple sources. Participants who own solar home products refer to it as "a back-up" to ensure continuity if the power goes out or they run out of PowerGen credit and are too cash strapped to top-up.

Cash flow constraints and affordability are also often intertwined with the need to prioritise competing obligations, such as fulfilling their roles within the family structure or the community and realising their aspirations to be frugal and careful in spending their hard-earned cash. As one single mother told us, as "the only breadwinner" with two children in a boarding school, "I plan my life smartly", hence, although electricity is "basic like food", "[financial] security is number one" (EL_F_37).

\subsection{Norms and aspirations}

When discussing what the benefits of electricity are and what services its arrival made possible, participants overwhelmingly emphasised values such as wellbeing, dignity, togetherness, reputation, role fulfilment as a parent, and emotional values such as comfort, entertainment and security. In terms of the actual service it delivers, "improved lighting" is the most mentioned benefit, followed by "for children to study" and "increased social activities". Grid-based lighting was rated highly as "reliable" (TE_F_43) and a "permanent" (TE_M_40) source, while over 70 per cent said children being able to study late into the evening was the most important benefit of electricity. A father of three children said them being able to "study at night is my main priority for electricity" (VI_M_31). A tea harvester said electricity is a basic need, mainly "for the kids, modern generation" (MW_M_40). Interviewees noted electricity has also allowed the adults to "extend chores time" (EL_F_32; EL_F_37; EL_M/F_43), "read my bible" (EL_M/F_39) and incentivise "the children to do their homework faster knowing that they can watch television" afterwards (TE_M_43).

When discussing entertainment and leisure activities (watching television and listening to music), respondents hinted at two distinct benefits: to strengthen social interaction and as a substitute for social interaction [35]. Some talked about how television and radio can act as a 
substitute for social interaction using constructs such as, "I do not feel that I am the only one in the house when everybody is out of the house working or at school" (VI_F_23), "I now watch television at home instead of going to the social hall" (TE_F_30; TE_M_35) and "music helps me to unwind" (EL_M_33). However, for most, the benefit of electricity lies in the fact that it allows for more "social activities" and more time "together" as a family and "increased night activities" with friends. As a way of explaining what "increased social activities" entails, two individuals within the electrified village of Elgon noted that "friends come to charge their phones" (EL_F_32; EL_F_29).

"Dignity" and "respect" are the two qualities many identified as attributes to having electricity. As one interviewee noted, earning "respect from visitors, especially those with no electricity" (EL_F_29) is important to her. In the context where every house is structurally identical, the arrival of electricity, and subsequently the appliances they purchase, has allowed some to differentiate themselves from the rest socially. As Warde [36] notes, depending on how they are perceived by society, some practices offer greater external social rewards than others. Staying up late, spending time together late into the evenings, and being able to invite neighbours and friends to watch television allows households to claim a social status among their peers. In her research into leisure time in Kenya, Essendi [37] observes that going to bed early is seen as what poor households that lack entertainment facilities do. The general perception is that affluent households have more leisure time, eat dinner late and watch television before going to bed in the late hours. During our school visits within the estate, teachers told us that in a short time period they had noticed an increase in students' learning performance. However, the teachers also said students from households with electrical entertainment appliances are more tired in the classroom, and their concentration levels have gone down.

We also found some correlation between income, appliance ownership, and attitudes about dignity and enhanced social relationships. As mentioned earlier (Section 4.1), households with two incomes own more appliances than single-income households. Two-income households are also more likely to mention "increased social activities" and "dignity" as important attributes to electricity than single-income households. For this group, social relationships and status appear to go together, and they seem to relish that electricity has enabled them to claim or strengthen these values. Moreover, strengthening social ties and improving social status appear to matter more to female participants. Nine of the 11 participants that identified 
"dignity" as a value are women. Women are also more likely to identify "security" as an important attribute of electricity: nine of the 13 respondents who said that security matters to them are women. Overall, activities such as inviting friends to charge their phones and norms such as dignity and respect from peers demonstrate how the interaction between technology (electricity), physical objects (outlet sockets, bulbs), energy practices (lighting, charging), and social norms (social status) constitute one aspect of an emerging new energy culture within the households in the estate.

Providing better futures for their children, maintaining ties with their kinship groups in their hometowns, and investing in their futures outside the tea estate are also some of the salient expectations and aspirations that strongly influence their modest consumption and investment in electrical appliances.

A review of households' spending patterns demonstrates that families spend 19 per cent of their incomes on their children's education while, on average, they allocate 2.8 per cent of their monthly incomes to electricity. Education within the tea estate follows the national education policy. The national education policy dictates that primary education is free, but for secondary education parents pay a fixed fee of about 14,000 KSh (140 USD) per year. Inside the estate, where there are two secondary schools, the same rules are applied. Thus, some parents with two or three children in secondary school reported that they pay 30,000 to 45,000 KSh (300 to 420 USD) per year. It is also common for parents to send their children to boarding schools or support their children's university-level education. For families in this group, spending on education goes as high as 75,000 (740 USD). Those we interviewed for this study overwhelmingly and unequivocally stated that education and study time is an important benefit of electrification. The value families place on education is not unique to estate employees, but rather a reflection of a broader social norm in Kenya. According to a survey conducted by the Central Bank of Kenya and the National Bureau of Statistics (2019), education is the highest priority and the leading life goal for Kenyans, cutting across income groups. Education is one of the top three reasons why Kenyans say they save and borrow money [38]. The survey also notes that for Kenyans buying assets and appliances such as televisions and refrigerators is the lowest priority, cutting across levels of education and wealth quintile.

Many of those interviewed for this study also said they contribute thousands of Kenyan shillings annually towards the education of their nieces, nephews and siblings. This is often in 
addition to regular cash remittances that workers send to relatives. Eighty-five per cent of the respondents said they send money to their parents, children or other relatives several times a year, or monthly. As migrant workers, kinship and maintaining ties with family members is an essential part of their identities. As migrants usually move from areas of low wages to areas of higher wages, remittances are an important source of income for the family. Remittance is also a meaningful way a migrant worker sustains and reproduces social relationships. Many send a significant portion of their incomes to maintain the emotional bonds with their kinship groups in anticipation of their eventual return to their hometowns [39].

The anticipation of their eventual return to their hometowns and the impermanent nature of life within the tea estate is an essential aspect of the migrant lifestyle that offers an insight into their modest electricity consumption. While away from home, migrant workers are generally motivated to spend the minimum to meet their basic needs, look after family members that remain in their hometowns, and save some money to be used for personal and family projects. During our interviews, for instance, many told us that they are saving or investing a portion of their income for acquisition and ownership of assets such as land, livestock and building materials in their hometowns. While the values households attach to education and social relationships justifies their consumption, their material context and way of life as migrant workers appear to be a factor that restrains excessive consumption.

\section{Conclusions}

We started this paper with the question of why electricity consumption among rural households in Kenya remains low. Using the James Finlay village electrification project as a case study, we explore how a broad range of factors including physical artefacts, social norms, daily routines and other environmental and institutional factors interact to motivate and restrict consumption. We examine how households incorporate electricity into their lives as manifested by the appliances they acquire, their energy-related daily routines, and norms and values they use to rationalise their investment in appliances or electricity consumption. Our findings show households are keen about the activities the grid-based electricity enables them to carry out; however, families are also cautious in their consumption. The arrival of electricity to the estate villages did not radically change the dominant household energy culture. For instance, regardless of how long they had been electrified, we observed no notable difference in appliance ownership between households that had access to electricity for three years and households that had access to electricity for three months. However, we also observed that the 
arrival of electricity has enabled families to reproduce and enact their norms and values in new ways.

Grid-based electricity appears to have an important influence on how households incorporate personal wellbeing and their notion of a good life and comfort in their day-to-day activities. Our findings show that electrification increases hopefulness in households' outlooks. Families are generally positive about connection and tend to position themselves as better off with electricity from the grid. For connected households, perceptions of their raised positions on the social ladder, as well as their life satisfaction, was evident. We also found that villagers who are waiting to be connected share this hopefulness and optimism. By enabling households to heighten their leisure activities, strengthen their social ties and invest in their children's futures, electricity has empowered families to articulate and realise intrinsic aspects of wellbeing in new ways.

However, electricity is also desired to the extent that it enables households to meet basic needs (performance and convenience), to carry out socially acceptable activities, and reproduce their personal and social norms. The arrival of electricity and their ability to acquire certain appliances has allowed some households to reproduce social relationships and family networks in new activities ranging from watching television together to letting friends charge their phones. On the other hand, with two-income households boasting more appliances, social norms like "dignity" and "respect" are now being expressed in different ways. In a way, gridbased electricity has enabled households to mark new boundaries and socially differentiate themselves in a community that otherwise (from the outside) looks the same. While social norms and routines shape the integration of electricity in households' daily routines, likewise, access to electricity is also remoulding the expression and communication of the very same routines, habits and norms.

Families' status as migrant workers has an overall constitutive effect on their energy culture within the estate. Not only do families not own (or even rent) the houses they live in, by the definition of their status as migrant workers, their relationships with the place and the physical infrastructure is provisional. Furthermore, inside the estate, using electricity for incomegeneration activities is not an option available to households, either due to the fact they are employed by the estate or because the 5amp limit limits the appliances they can operate. These restrictive elements are further reinforced by aspirations to maintain kinship in their hometown 
(remittance) and plan for life after the estate and their children's education, which takes precedence over other activities, such as purchasing more electrical appliances. Thus, for employees and their families, daily routines outside working hours emphasise unwinding and socialising. Essentially, although there is a functional element to consuming electricity, there is a strong hedonic aspect to households' energy cultures in the estate.

The broader conclusion we draw from this experience - i.e. the relevance of ways of life as migrant workers - is that highlights the relational and context-specific aspects of households' (energy) behaviours [19]. Furthermore, by bringing the lifestyle perspective into focus, we wanted demonstrate how different ways of living influence households' "internal logics of consumption" [40, p.217].

Our findings also show that when participants discuss money it is often less about the actual "money out of pocket" cost and more about how the service measures against their immediate expectations as well as long-term aspirations. As discussed here, there are a few reasons for it, including the fact that they already have established ways of meeting their energy needs. The grid-based electricity is being measured against access to free firewood and technologies (solar panels) that serve and meet families daily needs. With households juggling between solar, kerosene, electricity, charcoal and battery-operated appliances for lighting, cooking and entertainment, the arrival of electricity has resulted in an accumulation of energy options rather than in a linear transitioning from one to another. In relation to this, it is also worth noting that aided by technology (solar panels, smart metering and the pay-as-you-go system), households are increasingly taking charge and making choices on daily basis, therefore moulding their own distinct energy cultures. Families ability to switch from one energy source to another and opt in and opt out of accessing electricity from the grid is one other aspect of the emerging energy culture within the estate.

\subsection{Implications for policymakers and energy-service providers}

In Kenya, expensive subsidy programmes and expansive investments in infrastructure development have delivered impressive results in increasing grid penetration and connection in rural areas. However, with consumption lagging, stimulating demand and sustainable consumption is a concern for policymakers and energy-service providers, whose operation relies on revenue from users. Lower than expected consumption is also a concern from a perspective of ensuring that communities benefit from accessing clean and modern energy. The 
challenge policymakers face is then how to translate the technical and infrastructural gain into an opportunity to support social change and enhance communities' wellbeing in sustainable and just ways.

The case study we present in this paper shows that the relationship between the development of new systems of infrastructure and their integration into households' daily routines is a complex process. The cause and effect relationship between access and consumption is not self-evident. This follows the argument that energy consumption is not a linear process that can be captured in a single practice, but rather several different practices related to one another [13]. Here, the concept of "energy cultures" is useful as a way of seeing energy behaviour beyond the narrow focus of individual actors, to consider behaviour in wider contexts such as households and, in this case, a community of households, within a specific space and time [15]. The case study we present in this paper demonstrates that how consumers assimilate electricity into their everyday life cannot be understood independently of their physical and social context or devoid of social meaning. Accordingly, we argue that policy or programmatic efforts should adopt an integrated approach to understand how the underlying factors interact to shape energy behaviour, and, therefore, consumption patterns in different contexts.

If seen independently and in isolation, the various factors discussed in this paper - limited physical space, lack of electrical appliances, cash flow constraints, the 5amps load limit, access to alternative energy resources and migratory worker status - could potentially explain why consumption among households within the tea estate is modest. Such explanation could also lead to policy and programmatic interventions that potentially could resolve one or two of the identified barriers. Contrary to this, we argue for the virtues in seeing the multiple factors in an integrated way, i.e. not seeing one factor for what it is, but how it interacts with the other components. This approach calls for a comprehensive understanding of how the various elements come together to constitute subjects - whether individual households or communities - energy cultures. The complexities of these challenges require developing inter-disciplinary knowledge and skills as well as paying attention to consumer behaviour in different social and cultural contexts. By deepening understanding of how the different elements work together, while also paying attention to the agency role of actors, an integrated approach can help policymakers identify how energy cultures might be stimulated to change through direct and indirect interventions at various junctures. 
As noted earlier (Introduction), between 2010 and 2017 the utility company in Kenya increased its domestic customer base from 1.5 million to six million. This feat is down to electrification programmes that extended access to communities founded upon different ways of life, with distinct norms and social institutions. Ensuring the communities - with diverse lifestyles - are served sustainably will require establishing some basic understanding of their internal logics of consumption [40] in order to meet their needs. For instance, within the tea-estate villages, although demographically households are like any other rural communities, their energy culture is distinct due to the environmental and structural influences, technological configurations, norms and their migrant-worker status. If electrification is to deliver the benefits inherent to modern energy, we need to see households as embodiments of lifestyles that are informed and shaped by their situational and broader contexts as well as access to physical artefacts. The lesson we draw from the case study reinforces our argument for the need to see not only what motivates consumption, but also how everyday activities may drive or inhibit behaviour change. Finally, we note that these energy-related routines and experiences should not also be seen "as stable or fixed phenomena" [41, p. 450]. In doing things - whether it is watching television, staying up late to study or to spend time with family - new aspirations and norms arise, often persuading families to re-organise their priorities and preferences. Anticipating and understanding how household energy-consumption behaviour might evolve over time will be an important part of ensuring sustainable consumption. 


\section{References}

[1] J. Osiolo, H.H. Pueyo, A Gachanja, The Political Economy of Investment in Renewable Electricity in Kenya, IDS Bull. 48 (2017). doi:10.19088/1986-2017.166.

[2] Republic of Kenya, Kenya National Electrification Strategy: Key Highlights 2018, (2018). http://pubdocs.worldbank.org/en/413001554284496731/Kenya-NationalElectrification-Strategy-KNES-Key-Highlights-2018.pdf.

[3] J. Taneja, If you build it, will they consume? Key challenges to universal, reliable, and low-cost electricity delivery, CGD Working Paper, 491 Washington DC, 2019.

[4] S. Fobi, V. Deshpande, S. Ondiek, V. Modi, J. Taneja, A longitudinal study of electricity consumption growth in Kenya, Energy Policy. 123 (2018) 569-578. doi:10.1016/j.enpol.2018.08.065.

[5] M. Kamau, State slashes power output on low demand, Stand. (n.d.).

[6] M. McLoughlin. F. Duffy, A. Conlon, Charaterising domestic electricity consumption patterns by dwelling and occupant socio-economic variables: An Irish case study, Energy Build. 48 (2012) 240-248.

[7] R. V. Jones, A. Fuertes, K.J. Lomas, The socio-economic, dwelling and appliance related factors affecting electricity consumption in domestic buildings, Renew. Sustain. Energy Rev. 43 (2015) 901-917. doi:10.1016/j.rser.2014.11.084.

[8] H. Wallis, M. Nachreiner, E. Matthies, Adolescents and electricity consumption; Investigating sociodemographic, economic, and behavioural influences on electricity consumption in households, Energy Policy. 94 (2016) 224-234. doi:10.1016/j.enpol.2016.03.046.

[9] P. Burger, V. Bezenon, B. Bornemann, T. Brosch, V. Carabias-Hatter, M. Farsi, S.L. Hille, C. Moser, C. Ramseier, R. Samuel, D. Sander, S. Schmidt, A. Sohre, B. Volland, Advances in Understanding Energy Consumption Behavior and the Governance of Its Change â€" Outline of an Integrated Framework, Front. Energy Res. 3 (2015) 1-19. doi:10.3389/fenrg.2015.00029.

[10] K. Lee, E. Miguel, C. Wolfram, S. Berkouwer, E. Cascardi, R. Kannan, A. Kasimatis, Appliance Ownership and Aspirations among Electric Grid and Home Solar Households in Rural Kenya, Am. Econ. Rev. Pap. Proc. 106 (2016) 89-94. doi:10.1257/aer.p20161097.

[11] M.P. Blimpo, A. Postepska Why is Household Electricity Uptake Low in Sub-Saharan Africa?, Working Paper, World Bank, Washington, DC. (2017) 1-41.

[12] C. Wilson, H. Dowlatabadi, Models of Decision Making and Residential Energy Use, 
Pharm. Ztg. 150 (2005) 38-39. doi:10.1146/annurev.energy.32.053006.141137.

[13] K. Gram-hanssen, Understanding change and continuity in residential energy consumption, (2011). doi:10.1177/1469540510391725.

[14] E. Shove, Converging Conventions of Comfort, Cleanliness and Convenience, J. Consum. Policy. 26 (2003) 395-418.

[15] T. Hargreaves, M. Nye, J. Burgess, Keeping energy visible? Exploring how householders interact with feedback from smart energy monitors in the longer term, Energy Policy. 52 (2013) 126-134. doi:10.1016/j.enpol.2012.03.027.

[16] M. Shove, Elizabeth. Pantzar, Mika, Watson, The Dynamics of Social Practice: Everyday life and how it changes, Sage, London, 2012.

[17] K. Gram-hanssen, Residential heat comfort practices: understanding users, Build. Res. Inf. 38 (2010) 175-186.

[18] S. Gluck, Making energy cultures visible with situational analysis, Energy Res. Soc. Sci. 45 (2018) 43-55.

[19] J. Stephenson, B. Barton, G. Carrington, A. Doering, R. Ford, D. Hopkins, R. Lawson, A. McCarthy, D. Rees, M. Scott, P. Thorsnes, S. Walton, J. Williams, B. Wooliscroft, The energy cultures framework: Exploring the role of norms, practices and material culture in shaping energy behaviour in New Zealand, Energy Res. Soc. Sci. 7 (2015) 117-123. doi:10.1016/j.erss.2015.03.005.

[20] J. Stephenson, B. Barton, G. Carrington, D. Gnoth, R. Lawson, P. Thorsnes, Energy cultures : A framework for understanding energy behaviours, Energy Policy. 38 (2010) 6120-6129. doi:10.1016/j.enpol.2010.05.069.

[21] J. Stephenson, Sustainability cultures and energy research: An actor-centred interpretation of cultural theory, Energy Res. Soc. Sci. 44 (2018) 242-249. doi:10.1016/j.erss.2018.05.034.

[22] M. Jürisoo, N. Serenje, F. Mwila, F. Lambe, M. Osborne, Old habits die hard: Using the energy cultures framework to understand drivers of household-level energy transitions in urban Zambia, Energy Res. Soc. Sci. 53 (2019) 59-67. doi:10.1016/j.erss.2019.03.001.

[23] P.C. Stern, Individual and household interactions with energy systems: Toward integrated understanding, Energy Res. Soc. Sci. 1 (2014). doi:10.1016/j.erss.2014.03.003

[24] B.K. Sovacool, S.E. Ryan, P.C. Stern, K. Janda, G. Rochlin, D. Spreng, M.J. Pasqualetti, H. Wilhite, L. Lutzenhiser, Integrating social science in energy research, 
Energy Res. Soc. Sci. 6 (2015) 95-99. doi:10.1016/j.erss.2014.12.005.

[25] H. Wilhite, E. Shove, L. Lutzenhiser, W. Kempton, The Legacy of Twenty Years of Energy Demand Management: we know more about Individual Behaviour but next to Nothing about Demand, Soc. Behav. Clim. Chang. Mitig. (2006) 109-126. doi:10.1007/0-306-48160-х_4.

[26] E. Shove, G. Walker, What Is Energy For? Social Practice and Energy Demand, (2014). doi:10.1177/0263276414536746.

[27] A. McMeekin, D. Southerton, Sustainability transitions and final consumption: Practices and socio-technical systems, Technol. Anal. Strateg. Manag. 24 (2012) 345361. doi:10.1080/09537325.2012.663960.

[28] L. Lutzenhiser, S. Lutzenhiser, Looking at Lifestyle: The Impacts of American Ways of Life on Energy Demands and Pollution Patterns, ACEEE Summer Study Energy Effic. Build. (2006) 163-176.

[30] R. Ford, S. Walton, J. Stephenson, D. Rees, M. Scott, G. King, J. Williams, B. Wooliscroft, Technological Forecasting \& Social Change Emerging energy transitions : PV uptake beyond subsidies, Technol. Forecast. Soc. Chang. 117 (2017) 138-150. doi:10.1016/j.techfore.2016.12.007.

[31] M. Clandinin, Jean, Connelly, Narrative Inquiry: Experience and story in qualitative research, Jossey Bass Publishers, San Francisco, 2000.

[32] D. Miller, Why some things matter, in: D. Miller (Ed.), Mater. Cult. Why Some Things Matter, The University of Chicago Press, Chicago, 1998: pp. 2-23.

[33] I. Krumpal, Determinants of social desirability bias in sensitive surveys: a literature review, Qual. Quant. 47 (2013) 2205-2047.

[34] F. Bartiaux, K. Gram-hanssen, Socio-political factors influencing household electricity consumption : A comparison between Denmark and Belgium, ECEEE Summer Study. (2005) 1313-1325.

[35] S. Livingstone, The meaning of domestic technologies: a personal construct analysis of familial gender relations, in: E. Hirsch, R. Silverstone (Eds.), Consum. Technol. Media Inf. Domest. Spaces, Routledge, London, 1992.

[36] A. Warde, Consumption and theories of practice, J. Consum. Cult. 5 (2005) 131-153. doi:10.1177/1469540505053090.

[37] H.M. Essendi, Public perceptions of development and relationship with wellbeing: the case of Makueni County in Kenya, PhD Diss. Univ. Southampt. (2015).

[38] Finaccess, 2019 FINACCESS Household Survey, (2019). 
[39] J.O. Oucho, L.A. Oucho, V. Ochieng, Is Migration the Solution to Poverty Alleviation in Kenya ? Rural-Urban Migration Experiences of Migrants from Western Kenya to Kisumu and Nairobi, (2014).

[40] L. Lutzenhiser, M.H. Gosard, Lifestyles, status and energy consumption, Proc. ACEEE Summer Study Energy Effic. Build. 8 (2000) 207-222.

[41] M. Pantzar, E. Shove, Technology Analysis \& Strategic Management Understanding innovation in practice : a discussion of the production and re-production of Nordic Walking, 7325 (2010). doi:10.1080/09537321003714402. 